\title{
Physiological stress increases renal injury in eNOS-knockout mice
}

\author{
Mildred A Pointer ${ }^{1}$, Geraldine Daumerie ${ }^{2}$, LaKessha Bridges ${ }^{1}$, Sadiqa Yancey ${ }^{1}$, Kelly Howard ${ }^{1}$, Wendell Davis ${ }^{3}$, \\ Paul Huang ${ }^{4}$ and Joseph Loscalzo ${ }^{5}$
}

African Americans have a fourfold greater likelihood of developing end-stage renal disease (ESRD) compared with Caucasians. It has been proposed that the increased prevalence may be explained by non-traditional factors such as environmental stress and psychosocial factors. In this study, we used infrequent running to exhaustion as a physiological stressor to mimic real life experiences, such walking up stairs when an elevator is malfunctioning or running to catch a bus, to study its effect on renal injury in a hypertensive mouse model (endothelial nitric oxide synthase-deficient mice; eNOS ${ }^{-1-}$ ). This model has previously been shown to have renal injury comparable to that observed in African Americans. The effect of physiological stress on renal injury was examined in the setting of low $(0.12 \%)$, control $(0.45 \%)$ and high $(8 \%)$ dietary salt. Following bouts of physiological stress, eNOS ${ }^{-1-}$ mice had significantly greater interstitial inflammation compared with unstressed eNOS ${ }^{-1-}$ mice (two-way analysis of variance (2-ANOVA), Holm-Sidak; $P<0.01$ ). Interestingly, eNOS ${ }^{-1-}$ mice on a high-salt diet had greater interstitial inflammation compared with similarly stressed eNOS ${ }^{-I}$ mice on a low- or control-salt diet (2-ANOVA, Holm-Sidak; $P<0.03)$. These effects of stress were independent of systolic blood pressure $(141 \pm 7,143 \pm 4$, and $158 \pm 8$ vs. $141 \pm 4$, $138 \pm 5,150 \pm 4 \mathrm{~mm} \mathrm{Hg}$; end of study vs. baseline, respectively). There was no significant effect of stress or dietary salt on renal injury in control wild-type mice $\left(\mathrm{eNOS}^{+} /+\right)$. These data demonstrate that physiological stress exacerbates the renal injury associated with hypertension and that high-salt compounds this effect of stress. These results provide support for the idea that psychosocial and environmental factors contribute to the increased prevalence of ESRD in hypertensive African Americans.

Hypertension Research (2012) 35, 318-324; doi:10.1038/hr.2011.185; published online 15 December 2011

Keywords: kidney injury; salt; stress

\section{INTRODUCTION}

Hypertension is the second most common risk factor for kidney disease, second only to diabetes mellitus. ${ }^{1-4}$ Kidney disease, chronic kidney disease and end-stage renal disease (ESRD) have continued to increase over the past decade despite improvements in hypertension awareness, treatment and blood pressure control with treatment., ${ }^{2,5}$ One population that is particularly prone to ESRD is African Americans, a population that also has the highest hypertension prevalence rate. Of particular note is that hypertensive African-American males between the ages of 20 and 40 years are more prone to developing renal disease compared with other sectors of the population, having a 10-14 fold greater rate for developing ESRD. ${ }^{1}$ The general population of hypertensive African Americans has a fourfold greater likelihood of developing ESRD compared with Caucasians. Interestingly, the disparate incidence of ESRD between Caucasians and African Americans persists even at systolic blood pressure below $130 \mathrm{~mm} \mathrm{Hg}^{7}{ }^{7}$ The mechanism of the disparate renal disease rate in this population is not definitively known.

Bruce et al. ${ }^{89}$ have proposed that the reason for the striking differences in ESRD in African Americans may include factors beyond the traditional risk factors and associated pathophysiological pathway activation. These authors proposed that in addition to these traditional factors, psychosocial and environmental factors may contribute significantly to ESRD, especially within the African-American population. An environment of social stress, such as racism in combination with psychological responses of anxiety and depression, may explain the greater prevalence. Recent studies have shown that socioeconomic status is significantly correlated with chronic kidney disease and ESRD, ${ }^{8,10}$ particularly within African-American populations.

We have previously shown that the endothelial nitric oxide synthase (eNOS)-deficient mouse may be a model to study renal injury associated with hypertension as seen in African Americans. ${ }^{11}$ African

${ }^{1}$ Department of Biology, Julius L. Chambers Biomedical Biotechnology Research Institute, North Carolina Central University, Durham, NC, USA; ${ }^{2}$ Whitaker Cardiovascular Institute and Department of Medicine, Boston University School of Medicine, Boston, MA, USA; ${ }^{3}$ Biogen Idec, Department of Comparative Pathology, Cambridge, MA, USA; ${ }^{4}$ Massachusetts General Hospital, Boston, MA, USA and ${ }^{5}$ Department of Medicine, Brigham and Women's Hospital, Harvard Medical School, Boston, MA, USA

Correspondence: Dr MA Pointer, Department of Biology, Julius L. Chambers Biomedical Biotechnology Research Institute, North Carolina Central University, Durham, NC 27707, USA.

E-mail: mpointer@nccu.edu

Received 17 June 2011; revised 18 August 2011; accepted 7 September 2011; published online 15 December 2011 
Americans are characterized as having reduced bioavailable nitric oxide (NO) and the highest hypertension prevalence rates in the United States, and are salt sensitive. We showed that the renal injury seen in eNOS-deficient mice is similar to that described in African Americans, and that a high-salt diet exacerbates the hypertensionassociated renal injury. In this paper, we propose that the renal injury seen in hypertensive eNOS-deficient mice is exacerbated by physiological stress. Mice deficient in the vasodilator eNOS are hypertensive and exhibit significant renal injury. ${ }^{11-13}$ Therefore, in this study we examined the effect of physiological stress (periodic exposure to running to exhaustion) on renal injury in hypertensive eNOS-deficient mice. African Americans often have diets high in salt, which may be associated with tissue injury; for this reason, we also examined the effect of physiological stress in combination with a high-salt diet on renal injury in the hypertensive eNOS-deficient mice.

\section{METHODS}

\section{Animals}

Breeding pair stock for eNOS-knockout mice was obtained from the Jackson Laboratory (Bar Harbor, ME, USA; stock \# 002684) and Dr Paul Huang (Massachusetts General Hospital; Boston, MA, USA). Both were bred onto the background of the C57BL/6 wild-type control strain; thus, the C57BL/6 served as the control mouse strain. Wild-type control (C57BL/6) breeding stock was obtained from the Jackson Laboratory. All animals were maintained on regular rodent chow. Mice were entered into the study once they reached 6 months of age. Systolic blood pressure was measured using the tail-cuff method (Visitech 2000, Apex, NC, USA).

\section{Protocol}

Wild-type and eNOS-knockout mice were divided into three treatments groups. Mice were placed on either a low-salt $(0.12 \% \mathrm{NaCl}$; Harlan Teklad, Madison, WI, USA; cat. no.T7034), regular-salt $(0.4 \% \mathrm{NaCl}$; LabDiet, Richmond, IN, USA; cat. no. 5001$)$ or high-salt $(8 \% \mathrm{NaC}$; Harlan Teklad, cat. no.TD92012) diet for 8 weeks. Following baseline blood pressure measurements, mice were exposed to $4-5$ bouts of running to exhaustion, that is, mice were stressed about once every 2 weeks while on either the low-, regular-, or high-salt diets. Weekly tail-cuff blood pressures were taken throughout the study. During the weeks when both exercise and blood pressure measurements were performed, blood pressures were taken the day before or the day after exercise.

\section{Tail-cuff pressure measurements}

Mice tail-cuff blood pressures were measured using the BP2000 instrument by Visitech Systems. The room temperature was maintained at $\sim 72^{\circ} \mathrm{F}$ throughout this procedure. The mice were held in restrainers that were magnetically kept in place on a heated $\left(37^{\circ} \mathrm{C}\right)$ platform. The cuff was gradually inflated and systolic pressure was determined as that pressure when flow ceases as detected by a sensor. One to two weeks were allowed for the training of mice.

\section{Physiological stress protocol}

Mice were exercised to exhaustion using a six-lane small rodent treadmill (Exer3/6 Columbus Instruments, Columbus, OH, USA). The Exer-6M treadmill model was not equipped with the stimulus grid to avoid the added potential stress factor of electrical stimulation. The animals were protected from potential injury from the belt with a specially designed rear wall grid (Columbus Instruments).

Mice were acclimated to the treadmill by placing them on the treadmill for 5 min several days before initiation of the exercise regimen ( $\sim 2-3$ sessions). The exercise protocol was a modified version of that which has been used previously in both rats and mice. ${ }^{14,15}$ Specifically, mice were run to exhaustion once in every 14 days. The initial velocity of the treadmill was set at 11 meters per minute $\left(\mathrm{m} \mathrm{min}^{-1}\right)$ and $0 \%$ incline, and was increased by $0.5 \mathrm{~m} \mathrm{~min}^{-1}$ in every 4 min until exhaustion. Exhaustion was defined as refusal to continue to run after prodding.

\section{Tissue perfusion}

At the end of the study (exercise and diet regimen), the animals were anesthetized with isoflurane, the thoracic cavity was opened, and blood was collected from the left ventricle and placed in a (type blood collection tubeEDTA or without anticoagulant). To remove the remaining blood in the circulatory system and tissues, animals were perfused (via the left ventricle) with $\sim 5 \mathrm{ml}$ of phosphate buffered saline ( $\mathrm{pH} 7.4)$. Fixation was accomplished by perfusion of the circulatory system (or total body perfusion) with $\sim 5 \mathrm{ml}$ of $10 \%$ buffered formalin (Fisher, Pittsburgh, PA, USA, cat. no SF99-4). The kidney and heart were harvested, weighed, routinely processed, sectioned and placed on glass slides (Histotechniques, Powell, OH, USA). Sections of kidney were stained with Periodic acid Schiff.

\section{Histopathological evaluation and scoring}

Kidney sections were examined by a board-certified veterinary pathologist (WPD). Histopathological changes involving glomeruli, tubules, blood vessels and/or the interstitium were graded as either absent (0), minimal (1), mild (2), moderate (3) or severe (4). The sum of the severity scores from these regions was used to establish a total severity score for each animal. In addition, the distribution or extent of the renal injury was graded as being either focal (1), multifocal (2) or diffuse (global). The product of the severity score and distribution of renal injury was used to calculate an overall renal pathology score for each animal.

\section{RESULTS}

\section{Running to exhaustion}

The duration of each exhaustive running session is shown in Figure 1. There was no significant change in the time to exhaustion over the experimental period in among the three groups of $\mathrm{eNOS}^{-1-}$ mice $(0.12,0.45,8 \%$ dietary salt). Additionally, there was no statistical difference in the time to exhaustion between wild-type and eNOS ${ }^{-1-}$ mice (not shown; two-way analysis of variance (2-ANOVA). The time to exhaustion averaged $1614 \pm 373 \mathrm{~s}(n=33)$ for $\mathrm{eNOS}^{-1-}$ mice and $1384 \pm 286$ s for wild-type mice $(n=20)$.

\section{Effect of infrequent running to exhaustion on blood pressure}

Blood pressure was significantly higher in eNOS-deficient mice and remained unchanged over the course of the experimental protocol independent of the dietary salt (Figure 2). Specifically, post treatment blood pressures in eNOS $^{-1-}$ mice were $141 \pm 7,143 \pm 4$, and $158 \pm 8 \mathrm{~mm} \mathrm{Hg}$ on low-, control-, and high-salt diets, respectively;

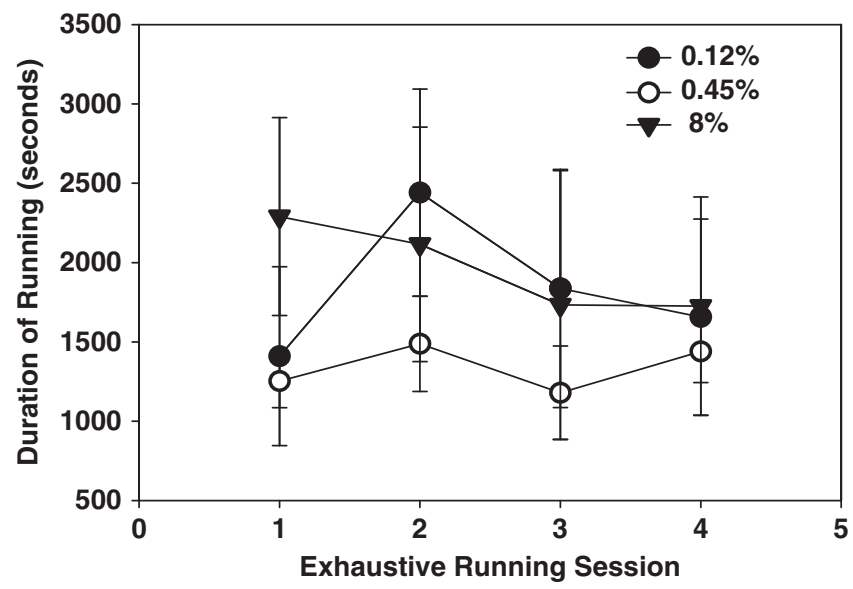

Figure 1 Duration of running to exhaustion for eNOS ${ }^{-1-}$ mice. Mice were exposed to four sessions of running to exhaustion; the time to exhaustion is plotted for each session for eNOS ${ }^{-I-}$ mice on low-salt $(0.12 \%$; $\bullet$ ); controlsalt $(0.45 \% ; \bigcirc)$ and high-salt $(8 \% ; \boldsymbol{\Delta})$ diets. 

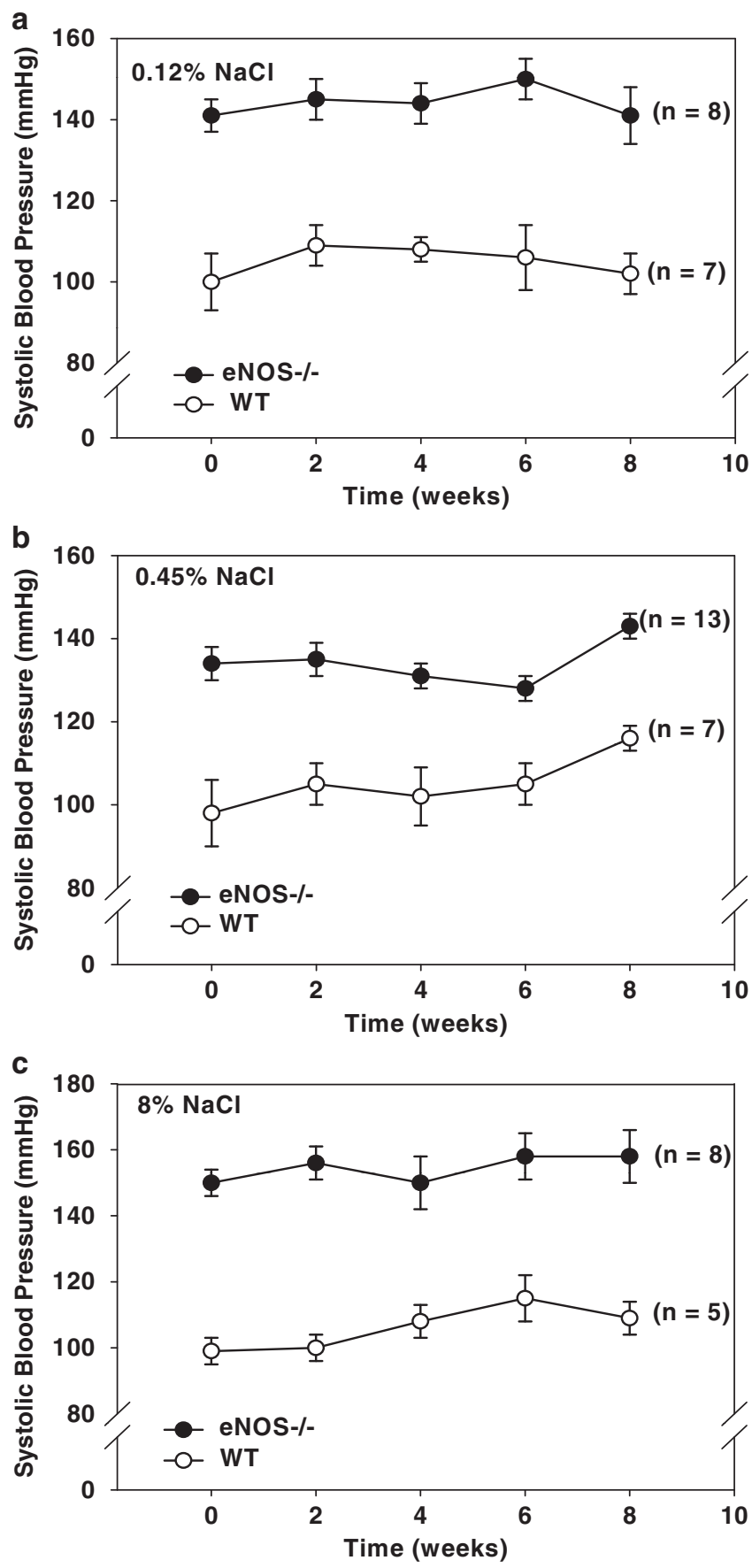

Figure 2 Systolic blood pressure over the 8-week study for wild-type (WT) and eNOS-knockout (eNOS ${ }^{-1-}$ ) mice. (a) The course of systolic blood pressure in WT $(O)$ and eNOS$^{-1-}(\bullet)$ during low-salt diet $(0.12 \%)$; (b) the course of systolic blood pressure in WT $(O)$ and eNOS ${ }^{-l-}(\bullet)$ during controlsalt diet $(0.45 \%)$; (c) the course of systolic blood pressure in WT $(O)$ and eNOS $^{-1-}(\bullet)$ during high-salt diet $(8 \%)$. Not significant over time (1-ANOVA) or between strains (2-ANOVA).

these blood pressures were not significantly different from baseline values of $141 \pm 4,138 \pm 5,150 \pm 4 \mathrm{~mm} \mathrm{Hg}$ for low-, control- and high-salt diets, respectively.

Baseline blood pressures in wild-type mice were $104 \pm 7,98 \pm 8$, and $102 \pm 4 \mathrm{~mm} \mathrm{Hg}$ on low-, control- and high-salt diets, respectively.
Blood pressure values were not significantly different from baseline at the end of the 8-week period in wild-type mice on low- and highsalt diets (102 $\pm 5,109 \pm 5 \mathrm{~mm} \mathrm{Hg}$, respectively, not significant); however, blood pressure was significantly increased in the control mice at the end of the 8 weeks on the control-salt diet $(116 \pm 3 \mathrm{~mm} \mathrm{Hg}$, $P<0.05$ vs. baseline).

\section{Physiological stress in wild-type mice}

Table 1 compares wild-type mice with and without the stress of running to exhaustion. Shown are the pathology scores for renal glomerular, perivascular, interstitial and tubular injury. There were no statistically significant effects of physiological stress on renal injury in wild-type mice (2-ANOVA, $P=\mathrm{NS}$ ).

\section{Physiological stress in eNOS-deficient mice}

Cardiac hypertrophy. Figure 3 shows the effect of the periodic stress of running to exhaustion on cardiac weight in NO-deficient mice. Two-way ANOVA did not reveal a significant effect of periodic running to exhaustion on cardiac weight $(P=\mathrm{NS})$; however, cardiac weight-to-body weight ratio was significantly lower in $\mathrm{eNOS}^{-1-}$ mice that were run to exhaustion while on a low-salt diet compared with eNOS $^{-1-}$ mice on a low-salt diet that were not run to exhaustion (3ANOVA and Tukey, $P<0.02)$. In contrast, $\mathrm{eNOS}^{-1-}$ mice that were run to exhaustion while on the control-salt diet had higher cardiac weight-to-body weight ratio compared with $\mathrm{NO}$-deficient mice that were not run to exhaustion (2-ANOVA and Tukey, $P<0.02$ ). There was no effect of exhaustive running on cardiac weight in $\mathrm{eNOS}^{-1-}$ mice on a high-salt diet.

Glomerular injury. Kidneys were evaluated for the presence of glomerular injury, including fibrosis, increased cellularity, thrombosis and/or sclerosis. As shown in Figures $4 \mathrm{a}$ and 5, periodic exposure to running to exhaustion significantly reduced the degree of glomerular injury in $\mathrm{eNOS}^{-1-}$ mice independent of dietary salt (2-ANOVA, $P<0.05)$; however, eNOS $^{-1-}$ mice on a high-salt diet had significantly greater glomerular injury (2-ANOVA, Holm-Sidak; $P<0.002$ ) as compared with $\mathrm{eNOS}^{-1-}$ mice on a low-salt diet independent of physiological stress.

Perivascular inflammation. When present, perivascular inflammation was characterized by infiltrates of mononuclear cells, primarily lymphocytes. Similar effects of physiological stress of running to exhaustion as seen with glomerular injury were observed for perivascular inflammation (Figure 4b); exposure to infrequent bouts of running to exhaustion decreased perivascular inflammation in eNOS $^{-1-}$ mice (2-ANOVA; Holm-Sidak, $P<0.04$ ). As was shown with glomerular injury, perivascular inflammation was significantly increased with high dietary salt in $\mathrm{eNOS}^{-1-}$ mice (2-ANOVA, Holm-Sidak; $P<0.02$ ).

Interstitial inflammation. Figure $4 \mathrm{c}$ shows the effect of periodic running to exhaustion on interstitial inflammation in $\mathrm{eNOS}^{-/-}$ mice. Unlike with glomerular injury and perivascular inflammation, bouts of exhaustive running significantly increased interstitial inflammation (2-ANOVA, Holm-Sidak; $P<0.01$ ).

Tubular injury. When present, tubular injury was primarily characterized by the presence of tubular dilation and protein casts. Although not statistically significant, periodic bouts of running to exhaustion tended to increase tubular injury on all salt diets 
Table 1 Effect of physiological stress on renal injury in control (WT) mice

\begin{tabular}{|c|c|c|c|c|c|}
\hline Strain & Salt diet, \% (n) & Glomerular damage & Tubular damage & Interstitial inflammation & Vascular inflammation \\
\hline \multirow[t]{2}{*}{ WT control } & $0.12(11)$ & $0.0 \pm 0.0$ & $1.1 \pm 0.4$ & $2.2 \pm 0.8$ & $0.6 \pm 0.6$ \\
\hline & $0.45(8)$ & $0.0 \pm 0.0$ & $1.1 \pm 0.4$ & $0.8 \pm 0.5$ & $0.1 \pm 0.1$ \\
\hline \multirow[t]{3}{*}{ WT exercise } & $0.12(6)$ & $2.0 \pm 2.0$ & $0.5 \pm 0.5$ & $0.5 \pm 0.5$ & $1.3 \pm 1.3$ \\
\hline & $0.45(5)$ & $1.2 \pm 1.2$ & $1.6 \pm 0.7$ & $3.6 \pm 1.6$ & $0.0 \pm 0.0$ \\
\hline & $8(6)$ & $0.0 \pm 0.0$ & $0.0 \pm 0.0$ & $1.5 \pm 1.5$ & $1.5 \pm 1.5$ \\
\hline
\end{tabular}

Abbreviation: WT, wild type.

Values $=$ mean \pm s.d.

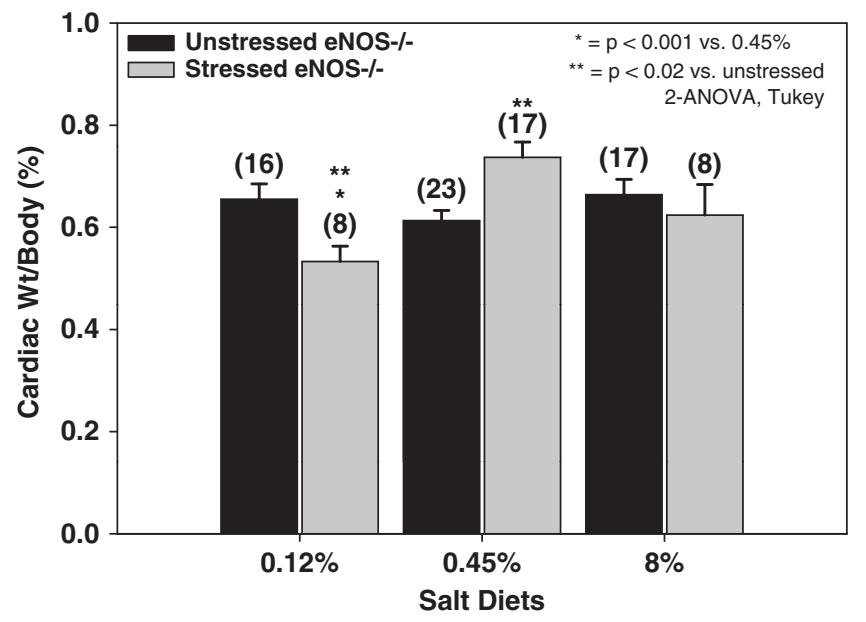

Figure 3 Cardiac weight to body weight $\left(\mathrm{mg} \mathrm{mg}^{-1} \times 100\right)$ ratio for wild-type (WT; black bars) and eNOS-knockout (eNOS ${ }^{-I-}$; gray bars) mice. ${ }^{*} P<0.001$ vs. control-salt diet $(0.45 \%), t$-test; ${ }^{* *} P<0.02$ vs. unstressed counterpart, 2-ANOVA and Tukey test.

(Figure 4d; 2-ANOVA, $P=\mathrm{NS}$ ). eNOS $^{-1-}$ mice exposed to physiological stress of running to exhaustion while on a high-salt diet had significantly greater tubular injury as compared with $\mathrm{eNOS}^{-1-}$ mice without exposure to bouts of exhaustive running (2-ANOVA, Holm-Sidak; $P<0.02$ ).

\section{DISCUSSION}

In this study, we demonstrated that the physiological stress of infrequent running to exhaustion may aggravate renal injury in hypertensive, NO-deficient mice. In particular, interstitial and tubular injuries were increased in hypertensive mice on a high-salt diet following several bouts of running to exhaustion. Importantly, this finding was independent of systolic blood pressure. In contrast, glomerular injury and perivascular inflammation were decreased following periodic physiological stress. Our results suggest that normal life stress may be a contributing factor to increased renal injury in the setting of reduced NO bioavailability and hypertension. These results may help to explain how psychosocial and environmental factors contribute to renal disease. ${ }^{8,10}$

ESRD is a major health burden in the United States resulting in an annual cost to Medicare of approximately $\$ 28$ million. There are only two treatments for ESRD: dialysis and renal transplantation. Hypertensive African Americans in general are four times more likely to have ESRD; however, there are sectors of this group of individuals that are 10-14 times more likely to have kidney disease. ${ }^{1}$ An explanation for this remarkable disparity is not currently available. Bruce et al. ${ }^{9}$ have offered that the unique experiences of life that include environmental stress, and the emotional and behavioral responses to the environment may explain the disparity. We, as well as others, have shown that in African American experiences of racism and the emotional response to it are associated with increased resting blood pressure, the second most important risk factor for ESRD. ${ }^{16-19}$ Studies have shown that daily struggles of life can have a significant impact on health and disease, particularly among hypertension in African Americans. ${ }^{20-22}$

One explanation for the predisposition of renal injury in African Americans could be a consequence of an imbalance between endogenous vasodilators and vasoconstrictors. African Americans are characterized as having reduced bioavailable NO, a major contributor to blood pressure regulation and tissue perfusion. ${ }^{23}$ Reduced bioavailable NO may be insufficient to mitigate the actions of an activated vasoconstrictor system on resistance blood vessels, the principal determinants of blood pressure and subsequent tissue perfusion. Thus, normal physiological elevations of vasoconstrictors may appear exaggerated in the presence of inadequate NO leading to greater reductions in tissue perfusion. The resulting impaired tissue perfusion may explain the predisposition to tissue injury.

In the current study, we used eNOS-null mice to examine the effect of physiological stress on the renal injury normally observed in this model. ${ }^{11}$ We have previously reported that the renal injury pattern includes glomerular sclerosis, interstitial inflammation and fibrosis, a pattern similar to that observed from biopsy samples from hypertensive African Americans. ${ }^{24-26}$ Therefore, we introduced the physiological stress of infrequent running to exhaustion, an event comparable to shoveling snow during winter, running to catch public transportation or climbing stairs to an apartment in housing developments. Running on a treadmill is often used as a stress test for humans, particularly when assessing cardiac and endothelial function. ${ }^{27-30}$ Running activates the sympathetic nervous system leading to the release of norepinephrine, a known stress hormone. ${ }^{31}$ In this study we used a modified version of previously published treadmill running regimen used for mice. ${ }^{15,32,33}$ Running to exhaustion was only to be considered as a stressor and not as training; consequently, we chose to expose the mice to the running until they were exhaustred once every 14 days. The training effect of exercise is seen with more frequent exposures such as a daily routine. ${ }^{34}$ Therefore, the infrequency of the running is not expected to lead to the benefits of regular exercise. Consequently, the running regimen is a stressor rather than exercise.

Using this model, we show that physiological stress of a real life experience such as infrequent running to exhaustion can exacerbate the renal injury usually associated with hypertension. Specifically, we show that tissue inflammation and tubular injury significantly increased in $\mathrm{eNOS}^{-1-}$ mice exposed to bouts of infrequent running 

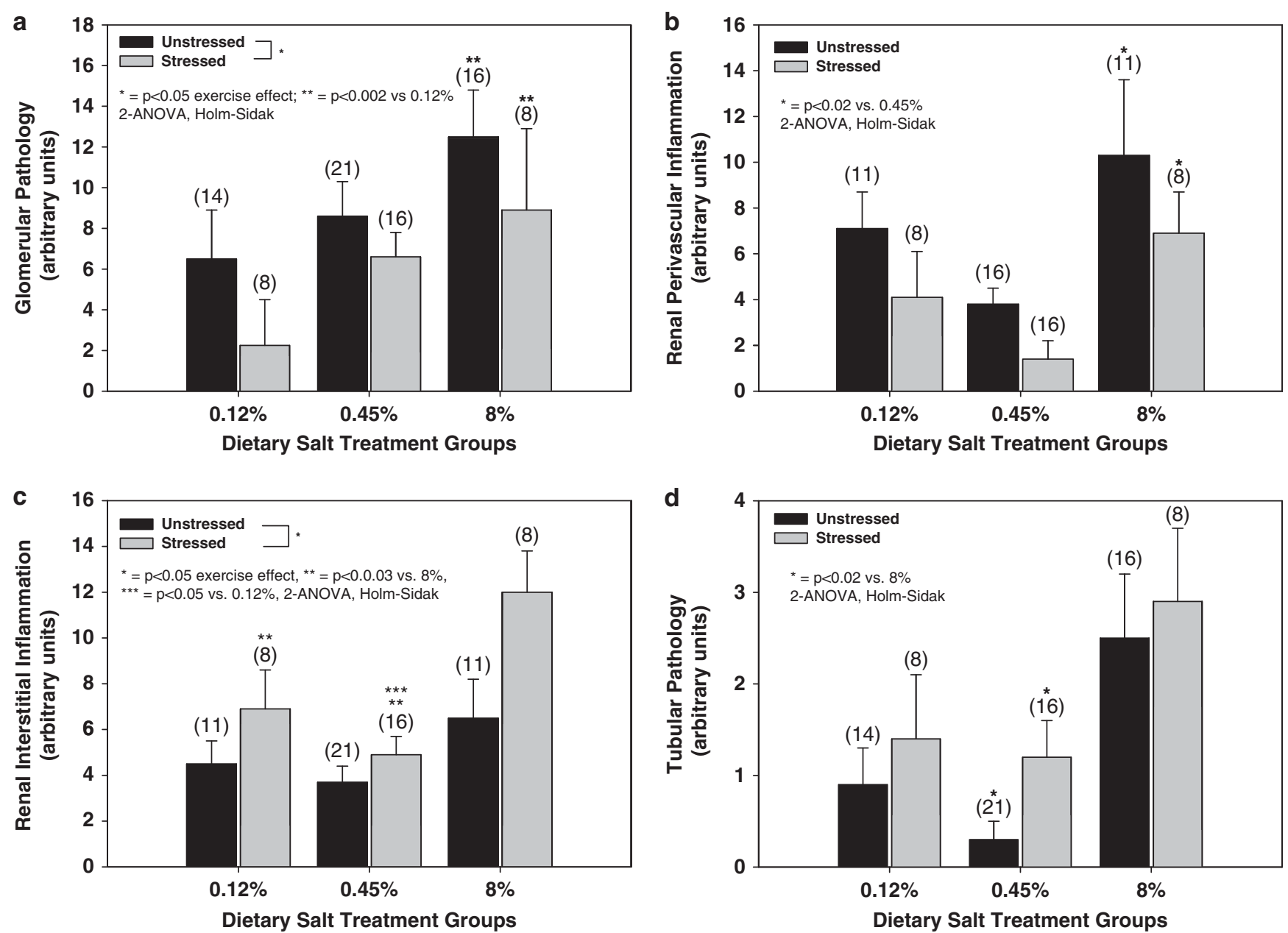

Figure 4 Renal injury scores for stressed (gray bars) and unstressed (black bars) eNOS-knockout (eNOS ${ }^{-l-}$ ) mice after the 8-week study. (a) The glomerular pathology scores; (b) perivascular injury scores; (c) renal interstitial inflammation scores and (d) tubular injury scores. Scores are shown for low- (0.12\%), control- $(0.45 \%)$ and high-salt diets $(8 \%)$.

to exhaustion. This finding is consistent with evidence that shows that target organ damage has a significant inflammatory component. ${ }^{35-38}$ Of particular interest is the observation that the experience of environmental stress, such as discrimination, is associated with increased C-reactive protein, an inflammatory marker, in a cohort of older African Americans. ${ }^{39,40}$

We further show that a high-salt diet adds to the effect of stress on renal injury. Specifically, interstitial inflammation is significantly greater in stressed $\mathrm{eNOS}^{-1-}$ mice on a high-salt diet compared with unstressed $\mathrm{eNOS}^{-1-}$ mice on high-salt diet. We have previously shown that a high-salt diet is associated with increased renal injury in eNOS $^{-1-}$ compared with WT control mice. ${ }^{11}$ This is the first demonstration that stress compounds the effect of high salt on renal injury.

The results of stress on cardiac hypertrophy revealed that physiological stress of infrequent running to exhaustion did not aggravate the hypertrophic action of long-standing hypertension in $\mathrm{eNOS}^{-1-}$ mice on low- and high-salt diet. However, stress increased the cardiac hypertrophy in mice on control-salt diet compared with unstressed mice. The reason for the differences in stress effect under varying salt diets is unclear. The lack of an effect of stress in the low-salt group may be the result of a protective action of a low-salt diet; others have shown that high dietary sodium chloride can promote tissue injury. ${ }^{41,42}$ Therefore, a low salt may be protective. ${ }^{43-45}$ Failure to see an increase hypertrophy in $\mathrm{NOS}^{-/-}$mice on a high-salt diet is unexpected as increased $\beta$-adrenergic ${ }^{46-48}$ and high salt both promotes hypertrophy. ${ }^{49-51}$ Perhaps the lack of an effect of stress in eNOS $^{-1-}$ mice on high-salt diet is explained by an inhibitory action of TNF $\alpha$ on $\beta$-adrenergic hypertrophic actions. ${ }^{52}$ TNF $\alpha$ has been shown to be elevated in $\mathrm{eNOS}^{-1-}$ mice ${ }^{53}$ and high salt also increases $\mathrm{TNF} \alpha^{54}$ Consequently, the elevated TNF $\alpha$ may counteract the effect of adrenergic system activation due to stress on hypertrophy. In the case of $\mathrm{eNOS}^{-1-}$ mice on control-salt diet, the combined effect of angiotensin II and adrenergic system activation may be unopposed by any inhibitory action of $\mathrm{TNF} \alpha$ on $\beta$-adrenergic system. More studies are needed to determine the interaction of salt and stress on cardiac hypertrophy, particularly in the setting of impaired NO bioavailability.

Thus, in this study, we demonstrate that the physiological stress of everyday life occurrences may exacerbate the renal injury associated with hypertension associated with NO deficiency. Furthermore, a high-salt diet may aggravate the effect of physiological stress on 
a
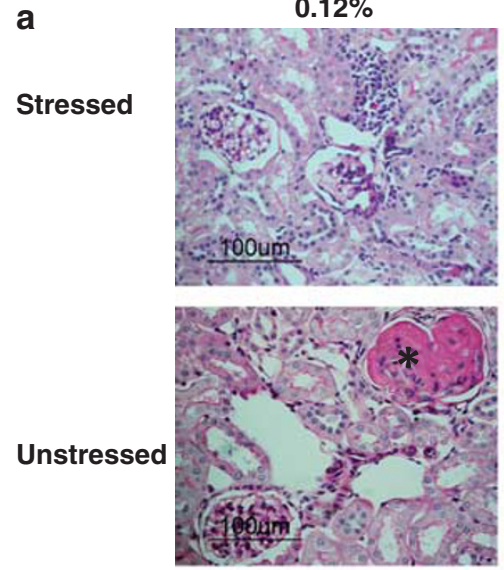

b
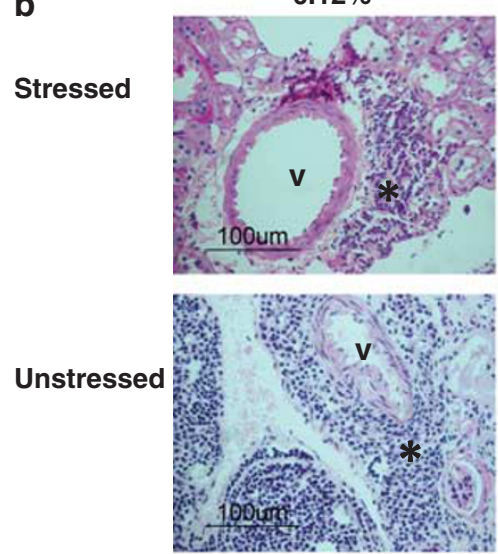

c

Stressed
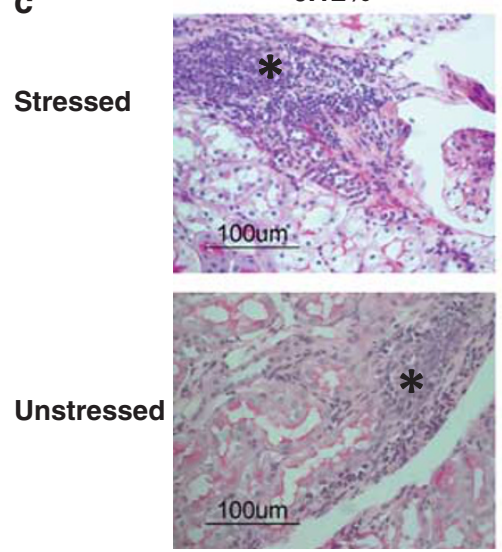

$0.45 \%$
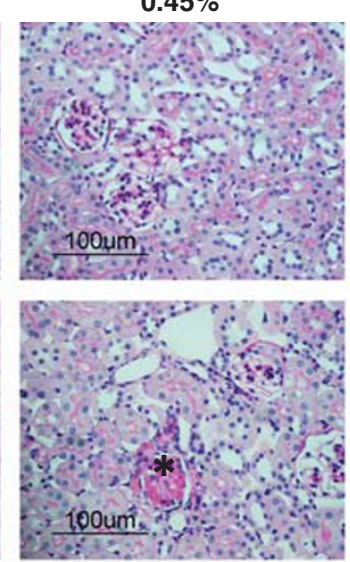

$0.45 \%$
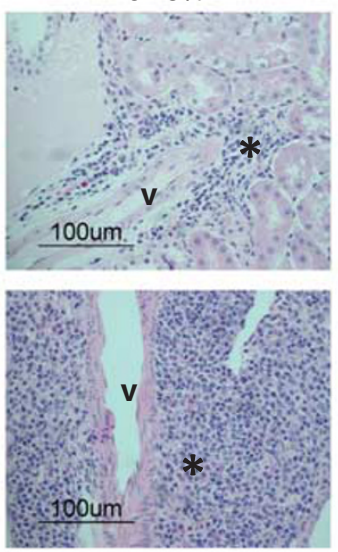

$0.45 \%$
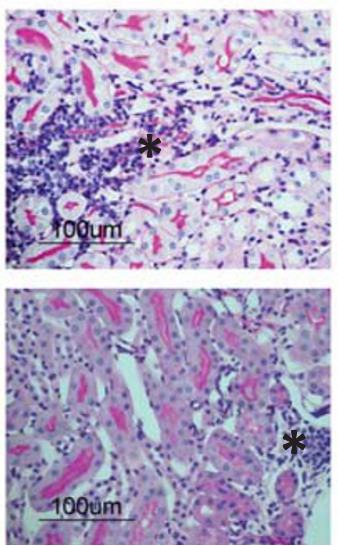
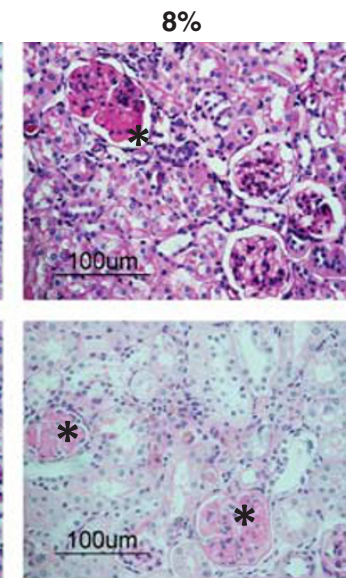

$8 \%$
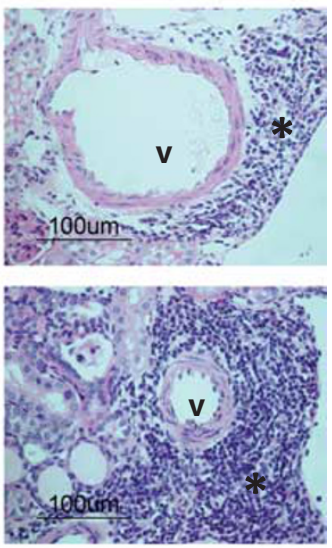

$8 \%$
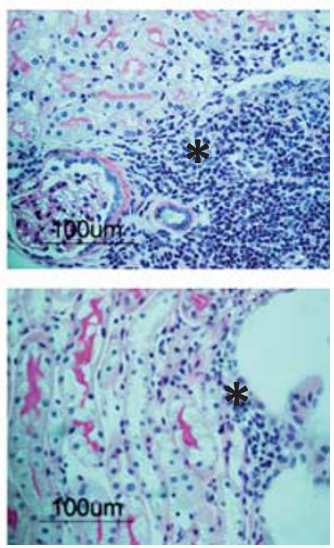

Figure 5 Representative histology slides of renal glomerular injury (a), perivascular inflammation (b) and interstitial inflammation (c) from stressed and unstressed eNOS ${ }^{-1-}$ mice. (a) Damaged glomeruli $\left(^{*}\right)$ in kidneys from stressed and unstressed eNOS ${ }^{-1-}$ mice on $0.12 \%$ (low), $0.45 \%$ (control) and $8 \%$ (high) salt diets. Normal glomeruli are more likely to be seen in stressed eNOS ${ }^{-l-}$ on each of the diets. (b) Inflammation (*) surrounding blood vessels (v) in kidneys from stressed and unstressed eNOS ${ }^{-1-}$ on low-, control- and high-salt diets. There is greater inflammation surrounding blood vessels from unstressed eNOS ${ }^{-1-}$ mice on all the three salt diets. (c) Renal interstitial inflammation $\left(^{*}\right)$ in kidneys from stressed and unstressed eNOS ${ }^{-1-}$ mice on low-, control- and high-salt diets. There is greater interstitial inflammation in stressed eNOS ${ }^{-1-}$ mice on all the three salt diets.

renal injury. These results are relevant to the clinical findings of a 4-14 fold greater prevalence of the kidney disease in African Americans who are characterized by impaired NO bioavailability, salt-sensitivity and unique environmental stresses, and who have a hypertension prevalence rate of almost $45 \%$. More studies are needed to characterize fully the inflammatory pathway, physiological correlates of stress and renal injury in this model.

\section{CONFLICT OF INTEREST}

The authors declare no conflict of interest.

\section{ACKNOWLEDGEMENTS}

This work was supported in part by NCMHD 000175, NHLBI UH1 HL59868, R01 HL64761, R25 HL59868 and NIGMS 2 S06 GM008049. 
1 National Institutes of Health, National Institute of Diabetes and Digestive and Kidney. US Renal Data System Atlas of End-Stage Renal Disease in the United States. National Institutes of Health, National Institute of Diabetes and Digestive and Kidney: Bethesda, MD, 2005.

2 National Institutes of Health, National Institute of Diabetes and Digestive and Kidney. US Renal Data System Atlas of End-Stage Renal Disease in the United States. National Institutes of Health, National Institute of Diabetes and Digestive and Kidney: Bethesda, MD, 2006.

3 National Institutes of Health, National Institute of Diabetes and Digestive and Kidney National Institutes of Health, National Institute of Diabetes and Digestive and Kidney: Bethesda, MD, 2009; II.

4 Xiao S, Wagner L, Schmidt RJ, Baylis C. Circulating endothelial nitric oxide synthase inhibitory factor in some patients with chronic renal disease. Kidney Int 2001; 59: 1466-1472

5 Schmidt RJ, Latos DL. Chronic kidney disease: the new epidemic and its impact on west virginia. WV Med J 2009; 105: 12-16, 18.

6 Sheps SG. Overview of JNC VI: new directions in the management of hypertension and cardiovascular risk. Am J Hypertens 1999; 12: 65S-72S.

7 Klag MJ, Whelton PK, Randall BL, Neaton JD, Brancati FL, Stamler J. End-stage renal disease in African-American and white men. 16-year MRFIT findings. JAMA 1997; 277: 1293-1298.

8 Bruce MA, Beech BM, Crook ED, Sims M, Wyatt SB, Flessner MF, Taylor HA, Williams DR, Akylbekova EL, Ikizler TA. Association of socioeconomic status and CKD among African Americans: The Jackson Heart Study. Am J Kidney Dis 2010; 55: 1001-1008.

9 Bruce MA, Beech BM, Sims M, Brown TN, Wyatt SB, Taylor HA, Williams DR, Crook E. Social environmental stressors, psychological factors, and kidney disease. J Investig Med 2009; 57: 583-589.

10 Crews DC, Charles RF, Evans MK, Zonderman AB, Powe NR. Poverty, race, and CKD in a racially and socioeconomically diverse urban population. Am J Kidney Dis 2010; 55: 992-1000.

11 Daumerie G, Bridges L, Yancey S, Davis W, Huang P, Loscalzo J, Pointer MA. The effect of salt on renal damage in eNOS-deficient mice. Hypertens Res 2010; 33: 170-176.

12 Huang PL, Huang Z, Mashimo H, Bloch KD, Moskowitz MA, Bevan JA, Fishman MC. Hypertension in mice lacking the gene for endothelial nitric oxide synthase. Nature 1995; 377: 239-242.

13 Shesely EG, Maeda N, Kim HS, Desai KM, Krege JH, Laubach VE, Sherman PA, Sessa WC, Smithies O. Elevated blood pressures in mice lacking endothelial nitric oxide synthase. Proc Natl Acad Sci USA 1996; 93: 13176-13181.

14 Kojda G, Cheng YC, Burchfield J, Harrison DG. Dysfunctional regulation of endothelial nitric oxide synthase (eNOS) expression in response to exercise in mice lacking one enos gene. Circulation 2001; 103: 2839-2844.

15 Patil RD, DiCarlo SE, Collins HL. Acute exercise enhances nitric oxide modulation of vascular response to phenylephrine. Am J Physiol 1993; 265: H1184-H1188.

16 Pointer MA, Livingston JN, Yancey S, McClelland MK, Bukoski RD. Psychosocial factors contribute to resting blood pressure in African Americans. Ethn Dis 2008; 18: 289-293.

17 Clark R, Anderson NB. Efficacy of racism-specific coping styles as predictors of cardiovascular functioning. Ethn Dis 2001; 11: 286-295.

18 Steffen PR, McNeilly M, Anderson N, Sherwood A. Effects of perceived racism and anger inhibition on ambulatory blood pressure in African Americans. Psychosom Med 2003; 65: 746-750.

19 Knudsen KD, Dahl LK, Thompson K, Iwai J, Heine M, Leitl G. Effects of chronic excess salt ingestion. Inheritance of hypertension in the rat. J Exp Med 1970; 132: 976-1000.

20 Gasperin D, Netuveli G, Dias-da-Costa JS, Pattussi MP. Effect of psychological stress on blood pressure increase: A meta-analysis of cohort studies. Cad Saude Publica 2009; 25: 715-726.

21 Brown DJ. Everyday life for black American adults: stress, emotions, and blood pressure. West J Nurs Res 2004; 26: 499-514.

22 Dressler WW. Hypertension in the African American community: social, cultural, and psychological factors. Semin Nephrol 1996; 16: 71-82.

23 Kalinowski L, Dobrucki IT, Malinski T. Race-specific differences in endothelial function: Predisposition of African Americans to vascular diseases. Circulation 2004; 109: 2511-2517.

24 Obialo $\mathrm{Cl}$, Hewan-Lowe K. Rapid progression to end-stage renal disease in young hypertensive African Americans with proteinuria. J Natl Med Assoc 1998; 90: 649-655.

25 Pat B, Hughson MD, Nicol JL, Hoy WE, Gobe GC. A comparison of pathomolecular markers of fibrosis and morphology in kidney from autopsies of African Americans and whites. Virchows Arch 2007; 450: 41-50.

26 Marcantoni C, Ma LJ, Federspiel C, Fogo AB. Hypertensive nephrosclerosis in African Americans versus caucasians. Kidney Int 2002; 62: 172-180.

27 Dilaveris PE, Zervopoulos GA, Michaelides AP, Sideris SK, Psomadaki ZD, Gialafos EJ, Gialafos JE, Toutouzas PK. Ischemia-induced reflex sympathoexcitation during the recovery period after maximal treadmill exercise testing. Clin Cardiol 1998; 21. 585-590.
28 Sen N, Tavil Y, Erdamar H, Yazici HU, Cakir E, Akgul EO, Bilgi C, Erbil MK, Poyraz F, Okyay K, Turfan M, Cemri M. Nebivolol therapy improves endothelial function and increases exercise tolerance in patients with cardiac syndrome x. Anadolu Kardiyol Derg 2009; 9: 371-379.

29 Luscher TF. Endogenous and exogenous nitrates and their role in myocardial ischaemia. Br J Clin Pharmacol 1992; 34: 29S-35S.

30 Kaufmann PA, Mandinov L, Seiler C, Hess OM. Impact of exercise-induced coronary vasomotion on anti-ischemic therapy. Coron Artery Dis 2000; 11: 363-369.

31 Mark AL, Victor RG, Nerhed C, Wallin BG. Microneurographic studies of the mechanisms of sympathetic nerve responses to static exercise in humans. Circ Res 1985; 57: 461-469.

32 Fernando P, Bonen A, Hoffman-Goetz L. Predicting submaximal oxygen consumption during treadmill running in mice. Can J Physiol Pharmacol 1993; 71: 854-857.

33 Fewell JG, Osinska H, Klevitsky R, Ng W, Sfyris G, Bahrehmand F, Robbins J. A treadmill exercise regimen for identifying cardiovascular phenotypes in transgenic mice. Am J Physiol 1997; 273: H1595-H1605.

34 Hambrecht R, Adams V, Erbs S, Linke A, Krankel N, Shu Y, Baither Y, Gielen S, Thiele H, Gummert JF, Mohr FW, Schuler G. Regular physical activity improves endothelial function in patients with coronary artery disease by increasing phosphorylation of endothelial nitric oxide synthase. Circulation 2003; 107: 3152-3158.

35 Jastrzebski M, Czarnecka D, Rajzer M, Kawecka-Jaszcz K. Increased levels of inflammatory markers in hypertensives with target organ damage. Kardiol Pol 2006; 64: 802-809; discussion 810-801.

36 Karpha M, Lip GV. The pathophysiology of target organ damage in hypertension. Minerva Cardioangiol 2006; 54: 417-429.

37 Ritz E. Hypertension and kidney disease. Clin Nephrol 2010; 74: 39-43.

38 Lahera V, Cachofeiro V, Balfagon G, Rodicio JL. Aldosterone and its blockade: a cardiovascular and renal perspective. Scientific World J 2006; 6: 413-424.

39 Albert MA, Ravenell J, Glynn RJ, Khera A, Halevy N, de Lemos JA. Cardiovascular risk indicators and perceived race/ethnic discrimination in the Dallas Heart Study. Am Heart J 2008; 156: 1103-1109.

40 Lewis TT, Aiello AE, Leurgans S, Kelly J, Barnes LL. Self-reported experiences of everyday discrimination are associated with elevated c-reactive protein levels in older African-American adults. Brain Behav Immun 2010; 24: 438-443.

41 Antonios TF, MacGregor GA. Deleterious effects of salt intake other than effects on blood pressure. Clin Exp Pharmacol Physiol 1995; 22: 180-184.

42 Boero R, Pignataro A, Quarello F. Salt intake and kidney disease. J Nephrol 2002; 15 : 225-229.

43 Dworkin LD, Benstein JA, Tolbert E, Feiner HD. Salt restriction inhibits renal growth and stabilizes injury in rats with established renal disease. J Am Soc Nephrol 1996; 7: 437-442.

44 Sen S, Young D. Effect of sodium deprivation on cardiac hypertrophy in spontaneously hypertensive rats: influence of aging. J Mol Cell Cardiol 1991; 23: 695-704.

45 Urabe A, Izumi T, Abe Y, Taniguchi I, Mochizuki S. Effects of eplerenone and salt intake on left ventricular remodeling after myocardial infarction in rats. Hypertens Res 2006; 29: 627-634.

46 Kannel WB, Castelli WP, McNamara PM, McKee PA, Feinleib M. Role of blood pressure in the development of congestive heart failure. The Framingham Study. N Engl J Med 1972; 287: 781-787.

47 Perrino C, Naga Prasad SV, Mao L, Noma T, Yan Z, Kim HS, Smithies O, Rockman HA. Intermittent pressure overload triggers hypertrophy-independent cardiac dysfunction and vascular rarefaction. J Clin Invest 2006; 116: 1547-1560.

48 Zhao M, Fajardo GA, Urashima T, Spin JM, Poorfarahani S, Rajagopalan V, Huynh DT, Connolly AJ, Quertermous T, Bernstein D. Cardiac pressure overload hypertrophy is differentially regulated by \{beta\}-adrenergic receptors. Am J Physiol Heart Circ Physiol 2011; 301: H1461-H1470.

49 Ferreira DN, Katayama IA, Oliveira IB, Rosa KT, Furukawa LN, Coelho MS, Casarini DE, Heimann JC. Salt-induced cardiac hypertrophy and interstitial fibrosis are due to a blood pressure-independent mechanism in wistar rats. J Nutr 2010; 140: $1742-1751$

50 Suematsu N, Ojaimi C, Recchia FA, Wang Z, Skayian Y, Xu X, Zhang S, Kaminski PM, Sun D, Wolin MS, Kaley G, Hintze TH. Potential mechanisms of low-sodium diet-induced cardiac disease: superoxide-No in the heart. Circ Res 2010; 106: 593-600.

51 Yoshida K, Kim-Mitsuyama S, Wake R, Izumiya Y, Izumi Y, Yukimura T, Ueda M, Yoshiyama $\mathrm{M}$, Iwao $\mathrm{H}$. Excess aldosterone under normal salt diet induces cardiac hypertrophy and infiltration via oxidative stress. Hypertens Res 2005; 28: 447-455.

52 Garlie JB, Hamid T, Gu Y, Ismahil MA, Chandrasekar B, Prabhu SD. Tumor necrosis factor receptor 2 signaling limits beta-adrenergic receptor-mediated cardiac hypertrophy in vivo. Basic Res Cardiol 2011; 106: 1193-1205.

53 Flaherty MP, Brown M, Grupp IL, Schultz JE, Murphree SS, Jones WK. eNOS deficient mice develop progressive cardiac hypertrophy with altered cytokine and calcium handling protein expression. Cardiovasc Toxicol 2007; 7: 165-177.

54 Gu JW, Tian N, Shparago M, Tan W, Bailey AP, Manning Jr RD. Renal nf-kappab activation and tnf-alpha upregulation correlate with salt-sensitive hypertension in dahl salt-sensitive rats. Am J Physiol Regul Integr Comp Physiol 2006; 291. R1817-R1824. 